\title{
Dust Storm Index Anomaly for Sand-Dust Events Monitoring in Western Iran and its Association with the NDVI and LST Anomalies
}

Zohre Ebrahimi-Khusfi ( $\square$ zohreebrahimi2018@ujiroft.ac.ir) University of Jiroft https://orcid.org/0000-0002-1036-6386

Fatemeh Roustaei

Ardakan University

\section{Research Article}

Keywords: air quality, dust pollution, vegetation cover, land surface temperature, remote sensing.

Posted Date: June 14th, 2021

DOl: https://doi.org/10.21203/rs.3.rs-282445/v1

License: (c) (1) This work is licensed under a Creative Commons Attribution 4.0 International License. Read Full License

Version of Record: A version of this preprint was published at Environmental Science and Pollution Research on September 16th, 2021. See the published version at https://doi.org/10.1007/s11356-02116416-7. 

NDVI and LST Anomalies

*a Department of Ecological Engineering, Faculty of Natural Resources, University of Jiroft, Jiroft, Iran. Email: Zohreebrahimi2018@ujiroft.ac.ir

${ }^{\mathrm{b}}$ Assistant Professor, Faculty of Natural Resources, Department of Nature Engineering, Ardakan University, Ardakan, Iran. Email: froustaei@ardakan.ac.ir; Telephone number: +989132539554

8

$9 \quad *$ Corresponding author:

10 Zohre Ebrahimi-Khusfi

11 Department of Ecological Engineering, Faculty of Natural Resources, University of Jiroft, Jiroft, Iran.

12 Email address: Zohreebrahimi2018@ujiroft.ac.ir 


\section{Abstract}

25 Sand-dust events (SDE) are an increasing concern in many arid and semi-arid regions of the world, which have severely

26 damaged air quality and human health in recent years. This study was conducted to monitor the SDE in western Iran

27 using the dust storm index anomaly (DSIA) during 2000-2018. The spatiot-emporal change detection and statistical

28 analysis were used to understand the impacts of normalized difference vegetation cover anomaly (NDVIA) and land

29 surface temperature anomaly (LSTA) on the SDE activities. The area has suffered from the highest dust pollution in

30 2004, 2009, and 2012 (DSIA>+40) while it experienced the lowest dust pollution in 2002 and 2017 (DSIA<-40).

31 Approximately $48 \%$ of western Iran experienced decreasing changes and $52 \%$ of the total area experienced increasing

32 changes in dust pollution during 2010-2018 compared to the previous years. Incremental changes in NDVIA and LSTA

33 were observed in $73.2 \%$ and $7.5 \%$ of the study area while their decreasing changes were observed in $26.8 \%$ and $92.5 \%$

34 of the total area, respectively. Spatially, regions affected by the increase in dust pollution are mainly distributed in the

35 eastern and southern regions of the study area. Significant effects of changes in anomalies of both terrestrial parameters

36 on DSIA were observed throughout the study period ( $\left.\mathrm{R}_{\text {LSTA-DSIA }}=+0.52 ; \mathrm{R}_{\text {NDVIA-DSIA }}=-0.41\right) ; \mathrm{P}<0.05$ ). It was also

37 found that spatial correlation between LSTA and DSIA as well as NDVIA and DSIA in many parts of the study area

38 were significant at the $95 \%$ confidence level $(|R|>0.45)$. These findings can be useful for decision-makers to assess

39 the risks of dust pollution and reduce its negative consequences in western Iran.

40 Keywords: air quality, dust pollution, vegetation cover, land surface temperature, remote sensing.

\section{1. Introduction}

42 Sand-dust events (SDE) are one of the most destructive processes of land degradation that can lead to desertification

43 and air quality degradation. This phenomenon usually occurs when the surface winds speed exceeds the wind erosion

44 threshold velocity (Shao 2008). During this process, particle matters from ultra-fine (less than $0.1 \mu \mathrm{m}$ in diameter) to

45 large coarse particles (greater than $10 \mu \mathrm{m}$ in diameter) enter the earth's atmosphere and results in increased air

46 pollution in different areas, especially desert regions. It has also caused serious damages to infrastructure, urban and

47 rural settlements, photovoltaic panels, public health, as well as to plant, animal, and human communities (Atafar et al. 
49 The level of air pollution caused by SDE in different parts of the world varied at different space and time scales, 50 depending on climatic conditions, terrestrial factors, and human activities (Chen et al. 2020; Ebrahimi-Khusfi et al. 51 2020b; Ebrahimi-Khusfi et al. 2020c; Guo et al. 2018). Therefore, identifying the associated drivers is essential to 52 reduce SDE hazards.

53 The dependence of sand-dust events (SDE) on climatic factors including, wind velocity, precipitation, and temperature 54 have been shown in various studies (Achakulwisut et al. 2018; Bolles et al. 2019; Mashat et al. 2018; Middleton 2019; 55 N'Datchoh et al. 2018; Tan 2016; Xu et al. 2020). Higher air temperature, less precipitation, and erosive winds resulted 56 in SDE intensification and air quality destruction. The normalized difference vegetation index (NDVI), as a proxy of 57 vegetation cover, affects the air quality by changing the surface roughness, soil moisture, storage capacity, and wind 58 erosion threshold velocity (Meng et al. 2018). Land surface temprature (LST) has also a key role in energy balance 59 over the earth's surface on the regional and global scales (Orhan et al. 2014). The LST can affect air quality through 60 changes in soil moisture content. As temperature increases, the evapotranspiration from the land surface increases and 61 the soil moisture content decreases. As a result, the adhesion between the soil particles is reduced and the soil particles 62 are more easily separated from the soil, thereby increasing the concentration of the particles in the atmosphere 63 (Ebrahimi-Khusfi et al. 2020c). On the other hand, the concentration of suspended particles and the type of particles 64 can affect the earth's surface temperature (Alseroury 2015; Kahya et al. 2016). Overall, these reports show the complex relationships between various climatic parameters, terrain factors, and air quality. In total, finding the relationships 66 between dust pollution and its controllong factors can be useful for decision-makers to assess the risks of dust pollution 67 and mitigate its negative consequences in arid and semi-arid regions of the world.

68 Iran is located in the arid belt of the eastern hemisphere and SDE are serious environmental problems that have 69 increased in this country and affected the concentration of suspended particulate matter over the past decades 70 (Maghsudi et al. 2017; Meng et al. 2018; Norouzi et al. 2017; Nouri 2019). The extent of desert lands in Iran is about $71907,300 \mathrm{~km}^{2}$ (Khosroshahi et al. 2009), 5\% of which is covered by sand dunes (Abbasi et al. 2019). The most important 72 sources of dust generation in Iran are sand dunes, dune fields, shrinkage wetlands, and abandoned agricultural lands.

73 According to the dust storm index (DSI), SDE activities in arid and semi-arid regions of eastern Iran had a weak 74 increasing trend between the years 2000-2014 and 2000-2016, respectively. Wind speed, rainfall, temperature, and 
75 vegetation were known as the most important factors controlling dust pollution in these regions (Ebrahimi Khusfi et 76 al. 2020; Khusfi et al. 2020).

77 In many previous studies, vegetation cover has been considered as the main terrestrial factor affecting SDE activities.

78 However, according to the research background, land surface temperature (LST) has also affected dust events and air

79 quality. The effect of climatic factors, soil moisture, vegetation cover, and human activity on SDE in some areas of 80 western Iran have been investigated in some past works (Akhzari and Haghighi 2015; Akhzari et al. 2014; Kamal et 81 al. 2019) but no attempt has been made to investigate the effect of NDVI anomaly (NDVIA) and LST anomaly (LSTA)

82 on the DSI anomaly (DSIA) across western Iran. This study has therefore attempted to address this issue. Moreover, 83 no attempt has been conducted to investigate the trend of spatiot-emporal variations in NDVIA, LSTA, and DSIA over 84 the past decades in the western regions of Iran. The DSI is the most suitable index for monitoring SDE during the long85 term period using the meteorological data (O’Loingsigh et al. 2014), which has been widely used in some previous 86 studies (Khusfi et al. 2020; McTainsh et al. 2007; O’Loingsigh et al. 2014). Therefore, in this study, it was used to 87 monitor the SDE from northwest to southwest of Iran.

88 The assumptions considered in this study are: (1) upward trend of dust pollution due to exacerbation of SDE in western 89 Iran, (2) decrease in NDVIA and increase in LSTA across the study region, and (3) their significant effect on changes 90 in air pollution caused by SDE throughout the whole monitoring period (2000-2018). Accordingly, the main objectives 91 of this study are to monitor SDE using the DSIA and to identify changes in NDVIA and LSTA, both temporally and 92 spatially. The ultimate goal of this study is to understand the spatiot-emporal relationships between the DSIA-NDVIA 93 and DSIA-LSTA in western Iran.

\section{2. Materials and methods}

\section{$95 \quad$ 2.1. Study Region}

96 Our study area covers the northwest to the southwest of Iran, comprising about one-third of the whole of Iran. The area 97 is situated between the latitudes of $25^{\circ} 35^{\prime} 30^{\prime \prime} \mathrm{N}$ to $36^{\circ} 60^{\prime} 00^{\prime \prime} \mathrm{N}$ and the longitudes of $45^{\circ} 55^{\prime} 45^{\prime \prime} \mathrm{E}$ to $56^{\circ} 26^{\prime} 15^{\prime \prime} \mathrm{E}$ 98 (Fig.1a). More than $75 \%$ of the study area is covered by dry and semi-dry lands (Fig.1b) and there exist various land 99 covers, temporal lakes, and wetlands in this region of Iran (Fig.1c). Most of the SDE in the area occurs in spring and 
summer (Kamal et al. 2019) when "Shamal" wind speeds is maximized and the rainfall is minimized (Alizadeh-

101 Choobari et al. 2016). Al-Howizeh and Al-Azim marshes are important sources of dust generation in southwestern

102 Iran (Cao et al. 2015b). Base on the digital elevation model (DEM) map, the average elevation in the area is 1000 meters above sea level (Fig. 1a). Figure (1a) also shows the geographical location of the study area and selected synoptic stations in western Iran.

\subsection{DSIA Estimation}

The SDE is one of the most important factors affecting air quality degradation, especially in arid and semi-arid regions of the world (Parajuli and Zender 2018). Understanding how air quality is affected by these events requires long-term data and analysis of variations trends. In the current study, the DSIA was used to monitor the SDE in western Iran. To calculate it, the long-term data on dusty days and the codes recorded for the SDE in synoptic stations are needed, which were obtained from the Meteorological Organization of Iran for the stations located in western Iran.

111 The dust codes were used to detect the type of SDE, including local, moderate, and severe events. The total number 112 of dusty days for some synoptic stations located in western Iran during the study period is shown in the supplementary 113 section. The spatial distribution maps of dusty days and the average speed of dusty winds in the study period are shown 114 in Fig.2a and Fig.2 b, respectively. Also, the direction of dusty winds that are drawn based on hourly wind speed and 115 wind direction data using WRPLOT8.0.2 software, is shown in Fig. 2c.

The DSIA calculation steps are summarized below:

(i) Calculation of the monthly DSI (DSI monthly) for each station over the study period using equation (1): (O’Loingsigh et al. 2014)

(ii) Estimation of the annual DSI (DSI annual) and the long-term DSI (DSI ${ }_{\mathrm{lt}}$ ) using equations 2 to 3 , respectively.

(iii) Calculation of the DSIA using the relation (4).

$$
D S I_{\text {monthly }}=\sum_{i=1}^{n}[(0.05 \times L D E)+M D E+(5 \times S D S)]_{i}
$$

$$
D S I_{\text {annual }}=\sum_{1}^{12} D S I_{\text {monthly }}
$$




$$
D S I A=\frac{D S I_{\text {annual }}-D S I_{l t}}{D S I_{l t}} \times 100
$$

126 where $\mathrm{n}$ is the number of dusty days per study month and i refers to the ith value of $\mathrm{n}$ stations for $\mathrm{i}=1-\mathrm{n}$. LDE 127 is the local dust event days (daily maximum dust codes: 07-09). MDE indicates the moderate dust event days (daily 128 maximum dust codes: 30 - 32, and 98). SDS shows the severe dust event days (daily maximum dust codes: $33-35$ ).

129 After calculating the monthly DSIA for all available synoptic stations from 2000 to 2018 , the annual mean DSIA 130 values were computed using the arithmetic mean method in Excel 2016 software. The annual DSIA values calculated 131 for all stations were then utilized to compute the mean annual DSIA for the whole area of Iran. Moreover, the annual 132 DSIA values were used to calculate the mean long-term DSIA in the study period (i.e., 2000-2018). Then, the Inverse 133 Distance Weighting (IDW) method, as a simple and widely used method to visualize the spatial changes of dust event 134 activities and air quality (Krasnov et al. 2016; Škrbić and Marinković 2019), was used to draw the spatial distribution 135 of DSIA across Iran for the study years and the long-term period. The DSIA produced maps were reclassified into two categories based on DSIA values greater and smaller than zero. The positive DSI anomalies (DSIA>0) show that the annual dust storm index was higher than the long-term mean value of DSI, while negative DSI anomalies (DSIA $<0$ ) indicate that the annual DSI amount was less than the long-term average amount of DSI. Finally, the percentage of

139 the area belonging to each class was obtained by dividing the number of pixels in each class by the total number of 140 pixels in the study area multiplied by 100.

\section{2.3. NDVIA and LSTA Estimation}

142 The LST, vegetation cover, and soil moisture are the principal factors affecting the rate of soil erosion, dust emissions, 143 and air quality (Dupont et al. 2014; Munson et al. 2011; Sirjani et al. 2019). Considering that the effect of soil moisture 144 on SDE activities in western Iran has recently been investigated by Kamal et al. (2019), while the effects of vegetation 145 cover and LST on these events have not been investigated so far, it is focused on the investigation of the effect of these 146 two terrestrial parameters on SDE in western Iran, in this work. For this purpose, the NDVI and LST datasets were 147 used in the current study, since their long-term data are available in 'https://earthdata.NASA.gov/' and have the same 

obtained from Moderate Resolution Imaging Spectroradiometer (MODIS) products. In total, 1296 granules of monthly MODIS-NDVI and LST products were downloaded from the mentioned data source, because western Iran is situated on the 3 tiles of granules of the MODIS Imagery and the monitoring period is 19 years (2000-2018). Monthly images

152 of tiles were mosaicked using ARC GIS 10.4.1 software and terrestrial variables anomaly were computed. For this 153 purpose, the monthly values of NDVI and LST were firstly averaged according to the following equations:

$$
N D V I_{\text {annual }}=\sum_{i=1}^{12} \frac{N D V I_{i}}{12}
$$

$$
L S T_{\text {annual }}=\sum_{i=1}^{12} \frac{L S T_{i}}{12}
$$

The long-term values of terrestrial variables were then computed based on the equations 7 to 8 :

$$
N D V I_{l t}=\sum_{i=1}^{19} \frac{N D V I_{\text {аппиаl }}}{19}
$$

$$
L S T_{l t}=\sum_{i=1}^{19} \frac{L S T_{\text {annual }}}{19}
$$

Here, NDVI ${ }_{\text {lt }}$ and LST ${ }_{\text {lt }}$ are values of the mean long-term NDVI and LST respectively.

Finally, the NDVIA and the LSTA for all study years were calculated as:

$$
N D V I A=\frac{N D V I_{i}-N D V I_{l t}}{N D V I_{l t}} \times 100
$$

$$
L S T A=\frac{L S T_{i}-L S T_{l t}}{L S T_{l t}} \times 100
$$

163 In the above equations, $\mathrm{NDVI}_{\mathrm{i}}$ and $\mathrm{LST}_{\mathrm{i}}$ refer to mean values of NDVI and LST in the $\mathrm{i}$ th year at each pixel level of 164 the study area.

\subsection{Statistical analysis}



in Equation (11).

$$
R=\frac{\sum_{i=1}^{n}\left(x_{i}-\bar{x}_{i}\right)\left(y_{i}-\overline{y_{i}}\right)}{\sqrt{\sum_{i=1}^{n}\left(x_{i}-\bar{x}_{i}\right)^{2}\left(y_{i}-\overline{y_{i}}\right)^{2}}}
$$

171 In which, $\mathrm{y}_{\mathrm{i}}$ is dependent or response variable (DSIA) and $\mathrm{x}_{\mathrm{i}}$ is independent or explanatory variable (NDVIA or LSTA).

$172 \mathrm{i}$ is the $\mathrm{i}^{\text {th }}$ variable in a given dataset with sample size n. $\bar{x}_{i}$ is the mean value of DSIA and $\overline{y_{i}}$ is the mean value of 173 the NDVIA and/or LSTA over the whole study period.

174 The correlation coefficient value varies between +1 and -1 , both of which indicate a strong correlation with the 175 different directions between the variables studied. Values close to zero indicate a weaker correlation between the two 176 variables.

177 In order to detect the spatial variations of DSIA, NDVIA, and LSTA, their spatial distribution maps were also prepared 178 for the years 2000-2009 and 2010 to 2018 using the IDW method. Finally, the quantity and the type of changes in the 179 study parameters were determined by subtracting the maps from each other in ARC GIS software.

\section{3. Results}

\subsection{SDE monitoring in western Iran}

182 In this study, the DSIA maps were prepared to display the spatial variations of SDE in the study area during the years 1832000 to 2018. In the produced maps (Fig. 3), red areas (DSIA>0) indicate areas that were more susceptible to SDE activities and had a greater effect on the increased dust pollution across western Iran during the study period. The areas affected by SDE during the second half of the study years were mainly distributed in the southern regions of the study area, while in the first half of the study years, their distribution was also observed in the western borders. The inter- 
the study area has suffered from higher severities of dust pollution during the years 2012, 2004, and 2009 because the maximum amounts of DSIA were observed in these years (DSIA>+40). In contrast, the area had the best conditions of air quality in 2002 and 2017, when the minimum SDE activity occurred (DSIA<-40).

191 In this study, to better understand the periodic variations in SDE as well as to identify areas that have experienced 192 worse conditions of air quality in western Iran, the DSIA changes trend was also investigated in two different decades 193 (2000-2009 and 2010-2018). In addition, the drought severity in the western parts of Iran was higher than in other parts 194 of Iran in 2009 (Modarres et al. 2016). Therefore, investigating the changes in DSIA during these two decades can also 195 help to better understand the changes in air quality caused by SDE before and after the most severe droughts occurred 196 in western Iran. The results are illustrated in Fig.5. As shown in this figure, minimum values of DSIA in both periods 197 were -100 (Fig.5; a-b), meaning that the weather in these areas did not experience any dust pollution during the study 198 sub-periods. In some years, for example in 2004 , when only $26 \%$ of the study area experienced positive anomalies in 199 DSI, dust pollution was more than in other study years, particularly in 2011, which was about $45 \%$ of western Iran had 200 anomalies greater than zero. This result indicates that the intensity of the SDE activity in 2004 was higher than in 2011 201 (DSIA $2004>$ DSIA $_{2011}$; Fig. 4), but these events occurred in a smaller area (Fig. 3), meaning that the regions were 202 highly susceptible to SDE. In contrast, the maximum values of positive anomalies in different parts of western Iran 203 were different. The maximum DSIA is estimated at 378 (Fig. 5a) and 234 (Fig. 5b) for the first and second half of the 204 study years, respectively.

205 Overall, $48.1 \%$ of western Iran has experienced decreasing changes and 51.9\% of the total area has experienced 206 increasing changes in SDE during the second period compared to the first period (Fig. 5c). In other words, there are $2073.8 \%$ more areas experiencing increased changes than those experiencing decreasing changes. Indeed, the overall slope 208 of the spatial changes throughout the monitoring period was weak and upward. The temporal variations in the DSIA 209 also showed a weak upward slope throughout the period (Fig. 4).

\subsection{Relationships between NDVIA and LSTA with SDE in temporal scale}

211 In addition to climatic factors, the physical characteristics of the earth's surface also have a significant effect on SDE 212 activity in different regions. Hence, the correlation analysis of both LSTA and NDVIA with DSIA has been performed 213 to explore the linkage between the anomaly of two terrestrial factors and DSI anomaly over the study period. 
214 In the annual time scale, the best vegetation conditions across western Iran were in 2018 (NDVIA= +12.5), 2000

215 (NDVIA=+9.4), $2011($ NDVIA=+6.4), and 2014 (NDVIA= +5.9) respectively. In contrast, the worse years were 2008

216 and 2009 (NDVIA= -10.3), 2004 (NDVIA= -7), and 2002 (NDVIA= -4) respectively (Fig. 6a). The western regions

217 of Iran experienced the best ground temperature conditions in 2017 (LSTA= -1.9), $2014(\mathrm{LSTA}=-1.5)$ and 2002

$218(\mathrm{LSTA}=-0.5)$ while experienced the worst conditions in $2011(\mathrm{LSTA}=+0.54), 2009(\mathrm{LSTA}=+0.27)$ and 2004

$219(\mathrm{LSTA}=+0.2)$ respectively. The investigation of temporal changes in the annual DSIA and the annual anomalies of 220 the terrestrial variables for the entire area over the study years (2000-2018) revealed the NDVIA and LSTA correlated

221 well with the DSIA (Fig.6; $a$ and b). The findings also indicated that the trend changes in the inter-annual LST

222 anomalies during the study years (Fig. 6b) were relatively similar to the trend changes in the annual DSI anomalies

223 (Fig. 4). However, the temporal variations of NDVIA have been the inverse of the DSIA variations over a long-term

224 period (Fig. 6a). Also, in the first half of study years, the rate of changes in the NDVIA and LSTA were -1.6 and +0.03 ,

225 while it was +1.03 and -0.13 for the second half of study years respectively.

\subsection{Relationships between NDVIA and LSTA with SDE in spatial scale}

227 The remotely sensed data retrieved from MODIS products for western Iran indicated that the average LST and vegetation cover over the study period was about $15{ }^{\circ} \mathrm{C}$ and $27 \%$ respectively. Additionally, the range of LST variations varied between $13^{\circ} \mathrm{C}$ and $15^{\circ} \mathrm{C}$ (Fig. 7b) and NDVI varied from -0.2 to 0.8 across western Iran (Fig. 7a).

The results of correlation analysis showed that the R-values between NDVIA-DSIA and LSTA-DSIA changed from +0.1 to -0.6 (Fig. $7 \mathrm{c}$ ) and 0.02 to 0.7 (Fig. $7 \mathrm{~d}$ ) in western Iran, respectively. In the study area, during the first and second sub-periods, the NDVIA changed from -14.5 to 10.2 (Fig. 8a) and -7.8 to 23.2 (Fig. 8b), respectively. Over the sub-periods mentioned above, the LSTA changed from -0.5 to 2.3 (Fig. 8d) and -0.7 to 1.6 (Fig. 8e) in the study area, respectively. The results obtained from the change detection analysis showed that vegetation losses occurred in about $27 \%$ of the study area, especially over the southern parts of the study region (Fig. 8c), where there has also been an increasing change in soil erosion during recent years (Fig. 5c). However, about $73 \%$ of the entire region has experienced incremental changes (Fig. 8c) that have resulted in a decrease in soil particle emissions over the second

238 half of the study years. The LSTA values during the years 2010-2018 (Fig. 8e) were less than the LSTA in the early 239 years (Fig. 8d). As seen in Fig. 8f, the decreasing changes in the LSTA occurred in $92.5 \%$ of the total area while the 240 increasing changes occurred in $7.5 \%$ of the study area during the study period. 


\subsection{SDE monitoring in western Iran}

243 The spatial distribution of areas susceptible to SDE may be different from year to year. In western Iran, the southern

244 and southwestern regions have experienced adverse air quality caused by SDE in most years (Fig. 3). These regions 245 have also experienced the dustiest days over the study period (Fig. 2a). One of the most important reasons is that there 246 are vast deserts in neighboring countries of western Iran that have a high potential for dust generation (Boloorani et al.

247 2013). Furthermore, the dried bed of the Hour Al-Azim wetland, as another major source of dust production in 248 southwestern Iran (Adib et al. 2018), is located on the border between Iran and Iraq. As shown in Fig (2c), Ahvaz is 249 located in the eastern region of Hour Al-Azim Wetland and the prevailing direction of dusty winds in this city is from 250 west to east. Therefore, when dust events occur, part of the eroded dust is injected from the dried bed of Hour Al-Azim 251 into the atmosphere of cities located near this international wetland, especially Ahvaz, and affects the air quality of 252 this region of Iran. Of note, the average speed of dusty winds in the southern and northern areas of the study area 253 varied from 8 to $10 \mathrm{~m} / \mathrm{s}$ and 10 to $13 \mathrm{~m} / \mathrm{s}$ over the monitoring period, respectively (Fig. 2b). However, during this 254 period, the number of dusty days across the southern half varied between 150 and 881 days, and in most areas of the 255 northern half varied between 2 to 150 days (Fig. 2c). This is probably because the southern regions are more sensitive 256 to SDE and winds with lower velocities can carry dust particles.

257 In western Iran, more than $40 \%$ of the total area has suffered from dust pollution during the years 2011, 2008, and 2582010 while less than $28 \%$ of the area experienced these conditions during the years 2004 and 2006, respectively (Fig. 259 3). As a whole, the annual DSI was greater than the long-term DSI (DSIA>0) across about $44 \%$ of the study area and 260 it was lower than the long-term DSI (DSIA $<0)$ in approximately $56 \%$ of the study area. The area affected by SDE in 261 the north of the study area has declined between 2014 and 2018. These results indicate a downward trend in dust 262 production in these areas, which is in line with the findings of Ghale et al. (2017), who showed that the activity rate of 263 SDE in these areas from 2014 onwards was lower than in previous years. The decline in DSIA after 2009 reflects a 264 decrease in soil particulate emissions and improved air quality across western Iran in recent years, which agrees with 265 the results of some past works (Kamal et al. 2019; Namdari et al. 2016). It is likely due to reducing some sand-dunes 266 activity (Abbasi et al. 2019) and the development of vegetation cover in some parts of the study area (Ebrahimi-Khusfi 267 et al. 2020b). 
The areas affected by air quality degradation are mainly distributed in the eastern and southern regions of the study area (Fig. 5c). Furthermore, the sensitivity of these regions to the SDE over the latter period was more than in other areas. Therefore, it can be concluded that the inhabitants of these areas were more exposed to environmental hazards caused by the SDE, while residents of other parts of the study area, especially the western ones, were somewhat safe

272 from the SDE hazards. In general, the border regions between Iran and Iraq experienced positive anomalies in both 273 study periods (Fig. 5; a and b), meaning that the region has suffered from dust pollution throughout the entire of study 274 period. These findings are in line with the findings of those who identified this area as the dustiest area in western Iran 275 (Dehghanpour et al. 2014; Javan and Teimouri 2019).

276 According to the hypothesis of the present study, long-term variations in NDVIA and LSTA had significant effects 277 on the activity rate of the SDE and the air quality across western Iran. This is further analyzed and discussed in the 278 following sections.

\subsection{Relationships between NDVIA and LSTA with SDE in temporal scale}

It is important to understand how changes in dust pollution across different regions depend on changes in its controlling factors (Ebrahimi-Khusfi et al. 2021). In recent years (2010-2018), the physical characteristics of the earth's surface and air quality have improved across western Iran (Figs. 4 and 6). Although a comprehensive study of the spatiotemporal variability of vegetation cover and LST has not been conducted for this region of Iran, improvement of vegetation conditions in recent years on the local scales in Iran (Nateghi et al. 2018), Mongolia (Nanzad et al. 2019) and China (Feng et al. 2017) have also been proven which are partly consistent with the findings of this study. The obtained results of statistical analysis showed that the annual DSIA had a significant positive correlation with the LSTA ( $\mathrm{R}=+0.52$, $\mathrm{P}<0.05$; Fig.6a and Table 1$)$ and a negative correlation with the NDVIA $(\mathrm{R}=-0.41, \mathrm{P}<0.05$; Fig. $6 \mathrm{~b}$ and Table 1) across the whole monitoring period. Although based on these results, it can be concluded that both variables affect DSIA changes in western Iran, land surface fluctuations had a greater impact on the DSIA than the NDVIA variations. In agreement with the findings of this work, the inverse and linear relationship between the dust emissions and vegetation cover have also been reported in many previous studies (Azoogh and Jafari 2018; Kergoat et al. 2017; Sofue et al. 2018). In addition, a recent study concluded that LST is one of the main factors controlling dust events in many arid and semi-arid regions of Iran because it has shown a significant direct relationship with changes

294 in DSI in these areas (Ebrahimi-Khusfi and Sardoo 2021), which also confirms the findings of the present study. 
In addition to the temporal change impact of terrestrial parameters on DSIA, their impact may vary from one place to another place. Hence, the spatial correlation analysis was conducted to explore the effect of spatial variability in the LSTA and NDVIA on the DSIA variations. Spatially, areas that have experienced the most dust pollution during the monitoring period, are mainly distributed in the vicinity of the inland wetlands (Fig. 5 and Fig. 1a). The increase of air quality degradation over these areas may be due to the destruction of the Bakhtegan, Meighan, Shadegan, and Hour Al-Azim wetlands in the western half of Iran (Ansari and Golabi 2019; Arsanjani et al. 2015; Ebrahimi-Khusfi et al. 2020a). The high susceptibility of many dried-up Iranian wetlands to SDE, which has been reported in some previous studies (Karami et al. 2021; Lababpour 2020; Sedaghat and Nazaripour 2020) is in line with the findings of this study.

The spatial correlation results showed that the NDVIA was negatively correlated with the DSIA in many parts of the study area (Fig. 7c). However, the LSTA was positively correlated with the DSIA in the whole of the study area (Fig. 7d). The results also showed that the NDVIA had different behavior in a small part of the study region, especially in higher elevation areas, because the vegetation anomaly was positively correlated with the DSIA. Moreover, these regions experienced less air quality destruction in most years of the study period base on DSIA monitoring maps (Fig.

3). Given that the source of dust pollution in the western parts of Iran is located in Iraq (Boloorani and Nabavi 2017),

310 hence it may be due to the transport of aeolian sediments from adjacent countries to these regions. Another reason may

311 be changing in land use and conversion of rangelands to agricultural lands due to overexploitation of groundwater which requires further climatic and terrestrial information to prove these assumptions. Also, given that the vegetation coverage in these areas is denser than in its adjacent western areas, this relationship is expected to be reversed as a result of further vegetation losses. Based on the results of the present study, the LSTA was positively correlated with the DSIA throughout the study area (Fig. 7d). Because the earth's surface temperature is significantly dependent on the air temperature (Good et al. 2017) and its increase can accelerate the process of evapotranspiration (Sun et al. 2016). As a result, soil moisture decreases and dust production increases since the wind erosion threshold velocity decreases (Chepil 1956; Fécan et al. 1998). In this study, it was also found that the relationship between LSTA and DSIA as well

319 as NDVIA and DSIA across arid and semi-arid regions was stronger than the humid and sub-humid regions. These 320 results show more susceptibility of drier climates to the ground physical characteristics fluctuations and soil deflation 321 than to wetter climates in western Iran. 
322 The periodic variations in the terrestrial variables anomalies revealed that the NDVIA value has significantly increased

323 in recent years compared to the early years (Fig. 8c). This implies an increase in vegetation cover in the second half of

324 the study years compared to the long-term average vegetation cover across western Iran. The incremental changes in

325 vegetation-covered surfaces in the northwest, southwest, and central areas of western Iran are almost consistent with

326 the findings of other researchers (Faramarzi et al. 2018; Sadeghi et al. 2017). Also, the outcomes indicated that the

327 LSTA value has dramatically decreased in the latter period than in the previous period (Fig. 8f) and had a significant

328 effect on DSIA (Fig. 6b). This finding is almost in agreement with the findings of An et al. (2018), who stated

329 that change in near-surface temperature was one of the main reasons for changes in Asian SDE over recent

330 years.

331 It was also observed that many areas affected by vegetation degradation are mainly different from those that have

332 suffered from rising ground temperatures from 2009 onwards. This can indicate the separate effect of these two ground

333 factors on the level of SDE activity, especially in this region of western Iran. It may be related to the type of land use

334 and the difference in the roughness of the land surface, assumptions that need more information to prove for western 335 Iran.

336 As a whole, given that the spatiot-emporal variations in the LSTA and NDVIA had a relatively notable effect on the

337 DSIA variations over western Iran during the study period, it can be deduced that the results of this study support the 338 hypotheses of this study.

\section{4. Conclusion}

340 In this study, the DSIA was applied for monitoring the air pollution caused by SDE in western Iran from 2000 to 2018.

341 The spatiot-emporal alterations in NDVIA and LSTA, as well as their correlations with the DSIA, were also 342 investigated in this work. Temporarily, the highest degradation in air quality occurred in 2012 and 2004 while the 343 lowest degradation occurred in 2017 and 2002 over western Iran. Spatially, about half of the study area which mainly 344 covers southern areas has suffered from dust pollution. Furthermore, this study showed that fluctuations in LSTA and 345 NDVIA had significant effects on SDE activities in western regions of Iran. Air quality improvement due to the 346 increase in NDVIA and the decrease in LSTA across a small area of the border between Iran and Iraq were other 347 achievements of the current study. Moreover, the dual behaviors of LSTA and NDVIA were observed in areas that 
348 experienced the least dust pollution during the monitoring period. However, the stronger correlation between these 349 variables and DSIA was mainly observed in the dustiest areas. Therefore, appropriate and adaptive measures should

350 be taken to reduce the environmental hazards caused by soil erosion and dust pollution for the residents of western

351 Iran, especially the southern areas of the study area, which were more sensitive to the SDE in most study years.

352 Proposed measures include the restoration of degraded vegetation, the identification of dust particle transport

353 pathways, and the development of heat-resistant vegetation windbreakers in these areas. Determining the contribution

354 of human activities in vegetation degradation is also of great importance, which is suggested to be examined in future

355 studies. Investigating the seasonal changes in LSTA and NDVIA and their effects on SDE activities across western

356 Iran is another interesting topic that is suggested to be addressed in future research.

\section{Acknowledgment}

358 The authors would like to acknowledge the Iran Meteorological Organization for providing accurate climatology data 359 and the National Aeronautics and Space Administration (NASA) for making the MODIS products that are freely 360 available.

\section{$361 \quad$ Declarations}

\section{Ethical Approval:}

363 Not applicable.

\section{Consent to Participate:}

365 Not applicable.

\section{Consent to Publish:}

367 Not applicable.

\section{Authors Contribution:}

369 ZE analyzed and interpreted the meteorological and remotely sensed data, and was a major contributor in writing the 370 manuscript. FR prepared maps and wrote the introduction section of the article. All authors read and approved the final 371 manuscript. 
No funding was received for conducting this study.

\section{Competing:}

375 The authors declare that they have no competing interests.

\section{Availability of data and materials:}

The datasets used during the current study are available from the corresponding author on reasonable request.

\section{References}

Abbasi H, Opp C, Groll M, Rohipour H, Gohardoust A (2019) Assessment of the distribution and activity of dunes in Iran based on mobility indices and ground data Aeolian Research 41:100539

Achakulwisut P, Mickley L, Anenberg S (2018) Drought-sensitivity of fine dust in the US Southwest: Implications for air quality and public health under future climate change Environmental Research Letters 13:054025

Adib A, Oulapour M, Chatroze A (2018) Effects of wind velocity and soil characteristics on dust storm generation in Hawr-al-Azim Wetland, Southwest Iran Caspian Journal of Environmental Sciences 16:333-347

Akhzari D, Haghighi S (2015) Effect of Vegetation Change of Source Area on Dust Storms Occurrence in the West of Iran ECOPERSIA 3:1133-1143

Akhzari D, Pessarakli M, Shayesteh K, Bashir Gonbad M (2014) Effect of Source Areas anthropogenic activities on dust storm occurrences in the Western Parts of Iran Environmental Resources Research 2:124-132

Alizadeh-Choobari O, Ghafarian P, Owlad E (2016) Temporal variations in the frequency and concentration of dust events over Iran based on surface observations International Journal of Climatology 36:2050-2062

Alseroury F The effect of pollutants on land surface temperature around power plant. In: Proceedings of 36th the IIER international conference, Bali, Indonesia, 2015.

Ansari A, Golabi MH (2019) Prediction of spatial land use changes based on LCM in a GIS environment for Desert Wetlands-A case study: Meighan Wetland, Iran International Soil and Water Conservation Research 7:64-70

Arsanjani TJ, Javidan R, Nazemosadat MJ, Arsanjani JJ, Vaz E (2015) Spatiot-emporal monitoring of Bakhtegan Lake's areal fluctuations and an exploration of its future status by applying a cellular automata model Computers \& Geosciences 78:37-43

Atafar Z et al. (2019) Proinflammatory effects of dust storm and thermal inversion particulate matter (PM 10) on human peripheral blood mononuclear cells (PBMCs) in vitro: a comparative approach and analysis Journal of Environmental Health Science and Engineering:1-12

Azoogh L, Jafari S (2018) Interaction of petroleum mulching, vegetation restoration and dust fallout on the conditions of sand dunes in southwest of Iran Aeolian research 32:124-132 
Bao L, Wang S, Sun H, Huang W, Wang G, Nan Z (2019) Assessment of source and health risk of metal (loid) s in indoor/outdoor dust of university dormitory in Lanzhou City, China Environmental Science and Pollution Research 26:32333-32344

Bolles K, Sweeney M, Forman S (2019) Meteorological catalysts of dust events and particle source dynamics of affected soils during the 1930s Dust Bowl drought, Southern High Plains, USA Anthropocene 27:100216

Boloorani AD, Nabavi S (2017) Characterization of dust storm sources in Western Iran using a synthetic approach. Advances in meteorology

Boloorani AD, Nabavi S, Azizi R, Bahrami H (2013) Characterization of dust storm sources in western Iran using a synthetic approach. In: Advances in meteorology, climatology and atmospheric physics. Springer, pp 415420

Cao H, Liu J, Wang G, Guang Y, Luo L (2015a) Identification of sand and dust storm source areas in Iran 7 doi:10.1007/s40333-015-0127-8

Cao H, Liu J, Wang G, Yang G, Luo L (2015b) Identification of sand and dust storm source areas in Iran Journal of Arid Land 7:567-578

Chen F et al. (2020) Asian dust-storm activity dominated by Chinese dynasty changes since 2000 BP Nature communications 11:1-7

Chepil W (1956) Influence of moisture on erodibility of soil by wind Soil Science Society of America Journal 20:288292

Dehghanpour A, Halabian A, Fallahpour M (2014) Spatial and temporal analysis of dusty days in Iran

Dupont S, Bergametti G, Simoëns S (2014) Modeling aeolian erosion in presence of vegetation Journal of Geophysical Research: Earth Surface 119:168-187

Ebrahimi-Khusfi Z, Ghazavi R, Zarei M (2020a) The Effect of Climate Changes on the Wetland Moisture Variations and Its Correlation with Sand-Dust Events in a Semiarid Environment, Northwestern Iran Journal of the Indian Society of Remote Sensing:1-12

Ebrahimi-Khusfi Z, Mirakbari M, Ebrahimi-Khusfi M, Taghizadeh-Mehrjardi R (2020b) Impacts of vegetation anomalies and agricultural drought on wind erosion over Iran from 2000 to 2018 Applied Geography $125: 102330$

Ebrahimi-Khusfi Z, Mirakbari M, Soleimani-Sardo M (2021) Aridity Index Variations and Dust Events in Iran from 1990 to 2018 Annals of the American Association of Geographers:1-18

Ebrahimi-Khusfi Z, Sardoo MS (2021) Recent changes in physical properties of the land surface and their effects on dust events in different climatic regions of Iran Arabian Journal of Geosciences 14:1-18

Ebrahimi-Khusfi Z, Taghizadeh-Mehrjardi R, Nafarzadegan AR (2020c) Accuracy, uncertainty, and interpretability assessments of ANFIS models to predict dust concentration in semi-arid regions Environmental Science and Pollution Research:1-15

Ebrahimi Khusfi Z, Roustaei F, Ebrahimi Khusfi M, Naghavi S (2020) Investigation of the relationship between dust storm index, climatic parameters, and normalized difference vegetation index using the ridge regression method in arid regions of Central Iran Arid land research and management 34:239-263 
Faraji M et al. (2019) Chemical composition of PM 10 and its effect on in vitro hemolysis of human red blood cells (RBCs): a comparison study during dust storm and inversion Journal of Environmental Health Science and Engineering:1

Faramarzi M, Heidarizadi Z, Mohamadi A, Heydari M (2018) Detection of vegetation changes in relation to normalized difference vegetation index (NDVI) in Semi-arid rangeland in western Iran Journal of Agricultural Science and Technology 20:51-60

Fécan F, Marticorena B, Bergametti G Parametrization of the increase of the aeolian erosion threshold wind friction velocity due to soil moisture for arid and semi-arid areas. In: Annales Geophysicae, 1998. vol 1. Springer, pp 149-157

Feng J, Li N, Zhang Z, Chen X (2017) The dual effect of vegetation green-up date and strong wind on the return period of spring dust storms Science of the Total Environment 592:729-737

Ghale YAG, Baykara M, Unal A (2017) Analysis of decadal land cover changes and salinization in Urmia Lake Basin using remote sensing techniques Nat Hazards Earth Syst Sci Discuss

Good EJ, Ghent DJ, Bulgin CE, Remedios JJ (2017) A spatiot-emporal analysis of the relationship between nearsurface air temperature and satellite land surface temperatures using 17 years of data from the ATSR series Journal of Geophysical Research: Atmospheres 122:9185-9210

Guo L, Xiong S, Wu J, Ding Z, Chen Y, Zhu L, Ye W (2018) Human activity induced asynchronous dune mobilization in the deserts of NE China during the late Holocene Aeolian Research 34:49-55

Jaszczur M, Koshti A, Nawrot W, Sędor P (2020) An investigation of the dust accumulation on photovoltaic panels Environmental Science and Pollution Research 27:2001-2014

Javan K, Teimouri M (2019) Spatial analysis of occurrence probability of dusty days in west and southwest of Iran Arabian Journal of Geosciences 12:1-13

Kahya C, Bektas Balcik F, Burak Oztaner Y, Guney B Determining Land Surface Temperature Relations with Land Use-Land Cover and Air Pollution. In: EGU General Assembly Conference Abstracts, 2016.

Kamal A, Wu C, Lin Z (2019) Interannual variations of dust activity in western Iran and their possible mechanisms Big Earth Data:1-16

Karami E, Zehtabian G, Khosravi H, Mesbahzadeh T, Zareh S, Behrang Manesh M (2021) Determination of lake sediments susceptibility to wind erosion and its role in dust formation (Parishan lake, Fars province) Researches in Earth Sciences 12:114-130

Kergoat L, Guichard F, Pierre C, Vassal C (2017) Influence of dry-season vegetation variability on Sahelian dust during 2002-2015 Geophysical Research Letters 44:5231-5239

Khosroshahi M, Khashki M, Moghaddam TE (2009) Determination of climatological deserts in Iran Iranian Journal of Range and Desert Research 16:96-113

Khusfi ZE, Khosroshahi M, Roustaei F, Mirakbari M (2020) Spatial and seasonal variations of sand-dust events and their relation to atmospheric conditions and vegetation cover in semi-arid regions of central Iran Geoderma 365:114225

Krasnov H, Kloog I, Friger M, Katra I (2016) The spatiot-emporal distribution of particulate matter during natural dust episodes at an urban scale PloS one 11:e0160800 
Lababpour A (2020) The response of dust emission sources to climate change: Current and future simulation for southwest of Iran Science of The Total Environment 714:136821

Maghsudi R, Kurd N, Poornajaf A (2017) Qualitative and quantitative evaluation of airborne microorganisms and the concentrations of particulate and respirable matter causing from dust storm in the air of Ilam City: Six-month cross sectional study scientific journal of ilam university of medical sciences 25:60-69

Mashat AWS, Alamoudi AO, Awad AM, Assiri ME (2018) Seasonal variability and synoptic characteristics of dust cases over southwestern Saudi Arabia International Journal of Climatology 38:105-124

McTainsh G, Tews E, Leys J, Bastin G (2007) Spatial and temporal trends in wind erosion of Australian rangelands during 1960 to 2005 using the Dust Storm Index (DSI) Australian Collaborative Rangeland Information System Commonwealth of Australia

Meng Z, Dang X, Gao Y, Ren X, Ding Y, Wang M (2018) Interactive effects of wind speed, vegetation coverage and soil moisture in controlling wind erosion in a temperate desert steppe, Inner Mongolia of China Journal of Arid Land 10:534-547

Middleton N (2019) Variability and trends in dust storm frequency on decadal timescales: Climatic drivers and human impacts Geosciences 9:261

Modarres R, Sarhadi A, Burn DH (2016) Changes of extreme drought and flood events in Iran Global and Planetary Change 144:67-81

Munson SM, Belnap J, Okin GS (2011) Responses of wind erosion to climate-induced vegetation changes on the Colorado Plateau Proceedings of the National Academy of Sciences 108:3854-3859

N'Datchoh E, Diallo I, Konaré A, Silué S, Ogunjobi K, Diedhiou A, Doumbia M (2018) Dust induced changes on the West African summer monsoon features International Journal of Climatology 38:452-466

Namdari S, Valizade K, Rasuly A, Sarraf BS (2016) Spatiot-emporal analysis of MODIS AOD over western part of Iran Arabian Journal of Geosciences 9:191

Nanzad L, Zhang J, Tuvdendorj B, Nabil M, Zhang S, Bai Y (2019) NDVI anomaly for drought monitoring and its correlation with climate factors over Mongolia from 2000 to 2016 Journal of arid environments 164:69-77

Nateghi S, Nohegar A, Ehsani A, Bazrafshan O (2018) Evaluation of vegetation changes based upon vegetation indices using remote sensing Iranian Journal of Range and Desert Research 24

Norouzi S, Khademi H, Ayoubi S, Cano AF, Acosta JA (2017) Seasonal and spatial variations in dust deposition rate and concentrations of dust-borne heavy metals, a case study from Isfahan, central Iran Atmospheric Pollution Research 8:686-699

Nouri H (2019) Impact of Regional Rangeland Cover Degradation on Increasing Dusty Days in West of Iran Journal of Rangeland Science 9:286-299

O'Loingsigh T, McTainsh G, Tews E, Strong C, Leys J, Shinkfield P, Tapper N (2014) The Dust Storm Index (DSI): a method for monitoring broadscale wind erosion using meteorological records Aeolian Research 12:29-40

Orhan O, Ekercin S, Dadaser-Celik F (2014) Use of landsat land surface temperature and vegetation indices for monitoring drought in the Salt Lake Basin Area, Turkey The Scientific World Journal 2014

Parajuli SP, Zender CS (2018) Projected changes in dust emissions and regional air quality due to the shrinking Salton Sea Aeolian research 33:82-92 
516 Pearson K (1909) Determination of the coefficient of correlation Science 30:23-25

517 Powell JT, Chatziefthimiou AD, Banack SA, Cox PA, Metcalf JS (2015) Desert crust microorganisms, their 518 environment, and human health Journal of Arid Environments 112:127-133 doi:https://doi.org/10.1016/j.jaridenv.2013.11.004

520 Sadeghi M, Malekian M, Khodakarami L (2017) Forest losses and gains in Kurdistan province, western Iran: Where do we stand? The Egyptian Journal of Remote Sensing and Space Science 20:51-59

Sedaghat M, Nazaripour H (2020) Monitoring variability of soil moisture in Hour-al-Azim Wetland and its relation to dust storms in southwest Iran Scientific-Research Quarterly of Geographical Data (SEPEHR) 29:133-145

524 Shao Y (2008) Physics and modelling of wind erosion vol 37. Springer Science \& Business Media,

525 Sirjani E, Sameni A, Moosavi AA, Mahmoodabadi M, Laurent B (2019) Portable wind tunnel experiments to study soil erosion by wind and its link to soil properties in the Fars province, Iran Geoderma 333:69-80

Škrbić BD, Marinković V (2019) Occurrence, seasonal variety of organochlorine compounds in street dust of Novi Sad, Serbia, and its implication for risk assessment Science of The Total Environment 662:895-902

529

Sofue Y et al. (2018) Satellite monitoring of vegetation response to precipitation and dust storm outbreaks in Gobi Desert Regions Land 7:19

Sun Z, Wang Q, Batkhishig O, Ouyang Z (2016) Relationship between evapotranspiration and land surface temperature under energy-and water-limited conditions in dry and cold climates Advances in Meteorology 2016

Tam WW, Wong TW, Wong AH (2012) Effect of dust storm events on daily emergency admissions for cardiovascular diseases Circulation Journal 76:655-660

Tan M (2016) Exploring the relationship between vegetation and dust-storm intensity (DSI) in China Journal of Geographical Sciences 26:387-396

$\mathrm{Xu} C$ et al. (2020) Spatiot-emporal variations and driving factors of dust storm events in northern China based on hightemporal-resolution analysis of meteorological data (1960-2007) Environmental Pollution 260:114084 doi:https://doi.org/10.1016/j.envpol.2020.114084 
Figures

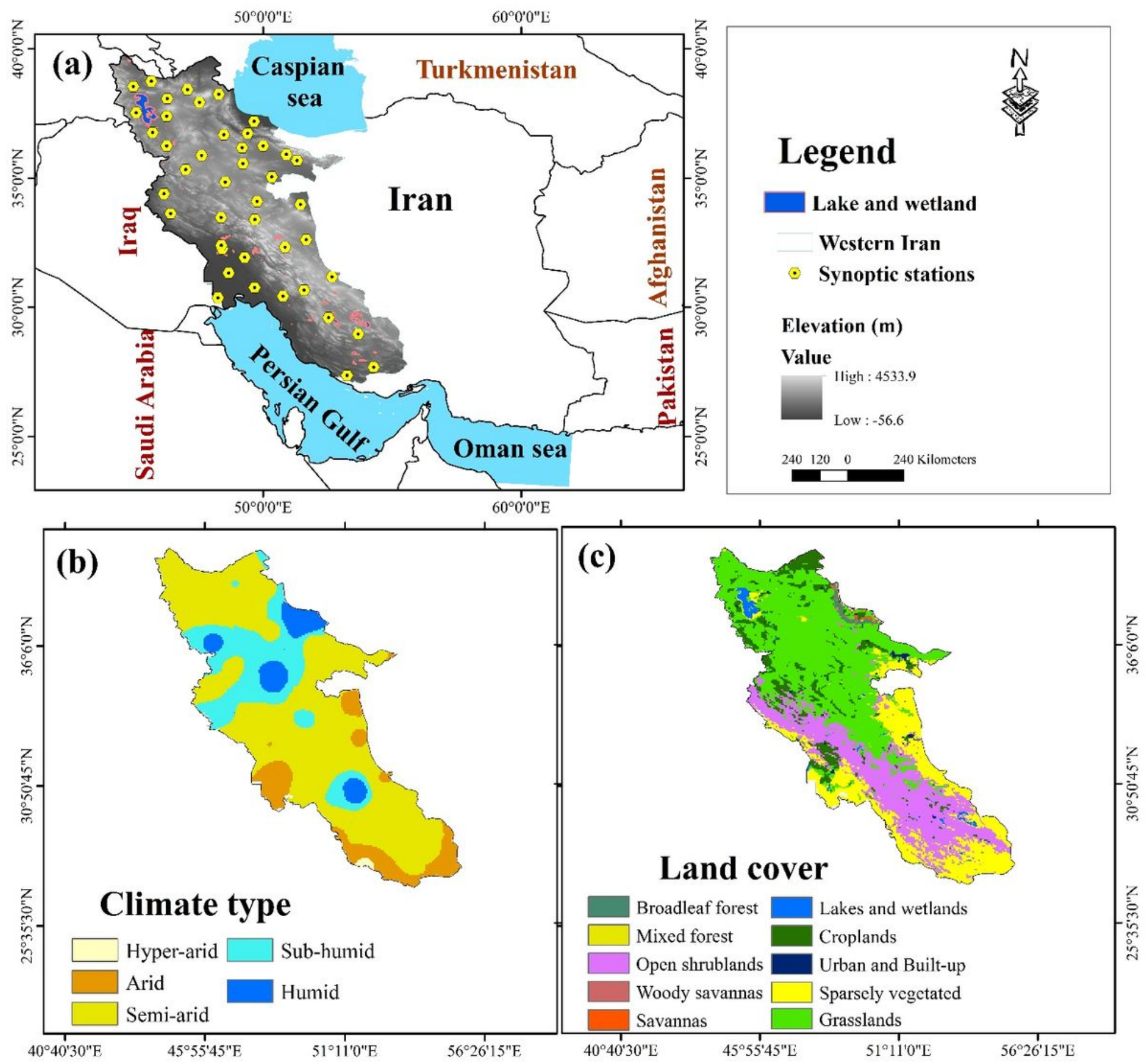

Figure 1

(a) Situation of the study area and synoptic stations in Iran, (b) different climate regions, and (c) land cover maps in western Iran. 


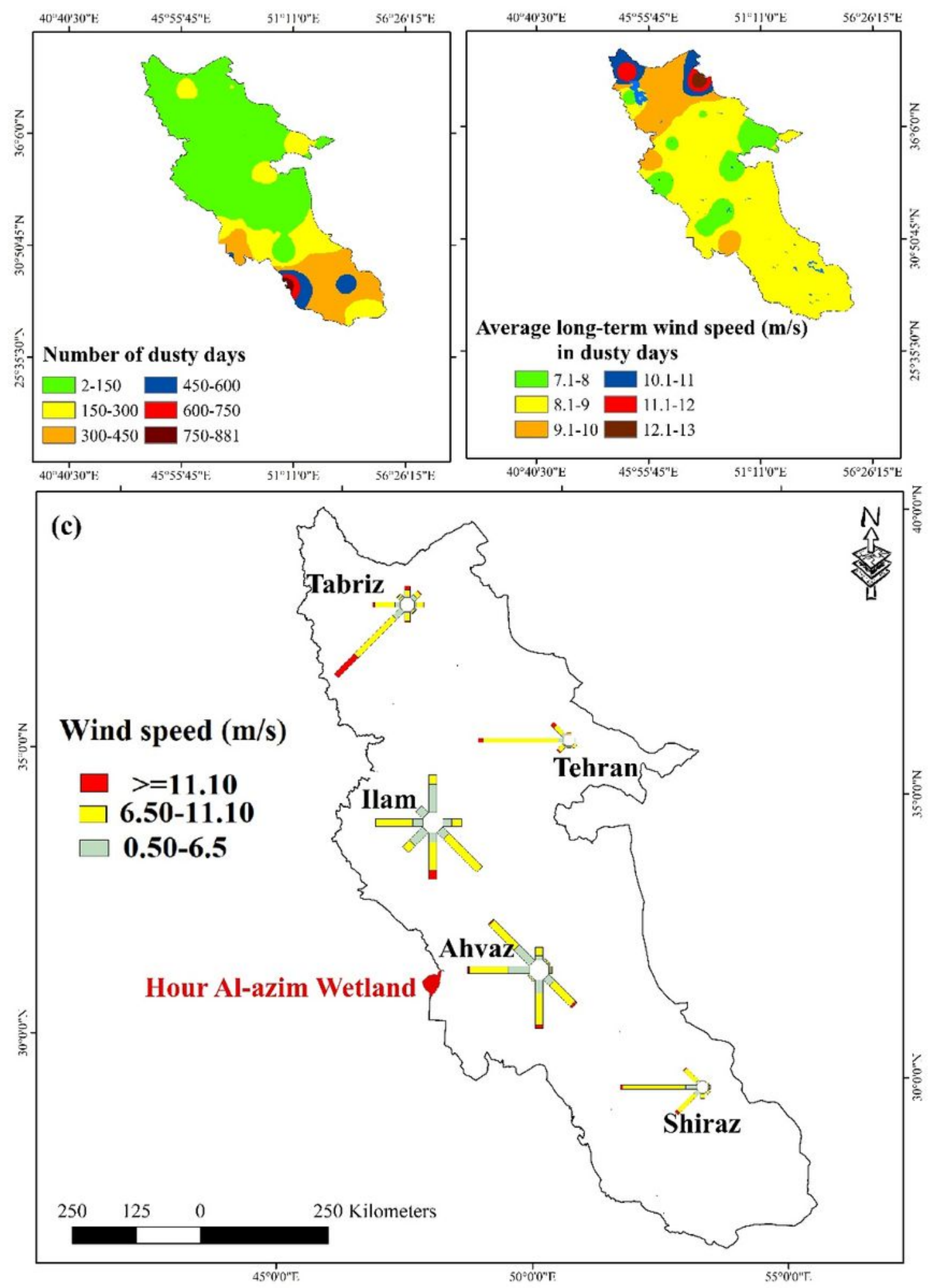

Figure 2

(a) Spatial distribution of number of dusty days, (b) average wind speed, and (c) directions of dusty winds during 2000-2018 in western Iran. 


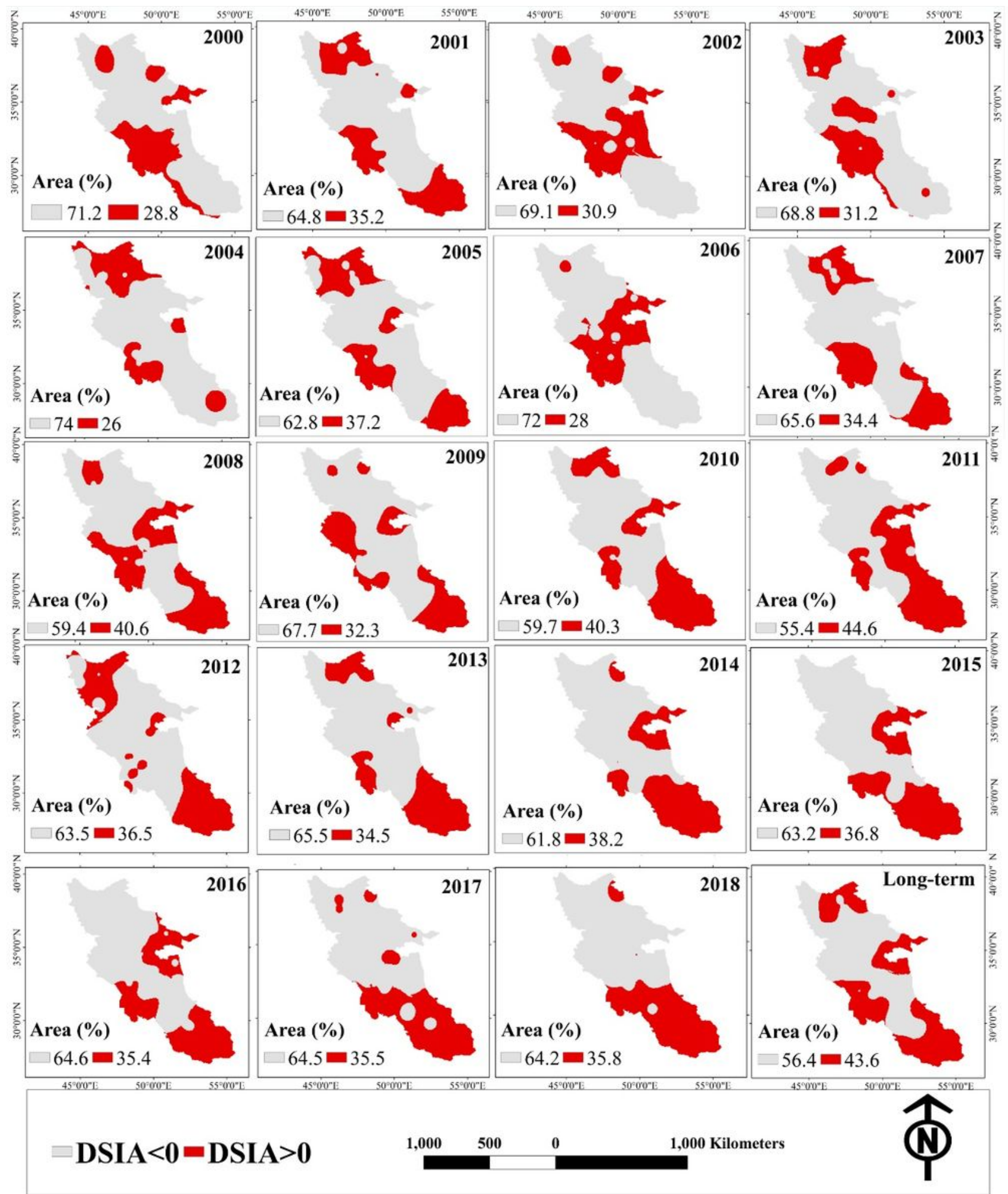

Figure 3

The spatial distribution of low-dust areas $(D S I A<0)$ and high-dust areas $(D S I A>0)$ in western Iran from 2000 to 2018. 


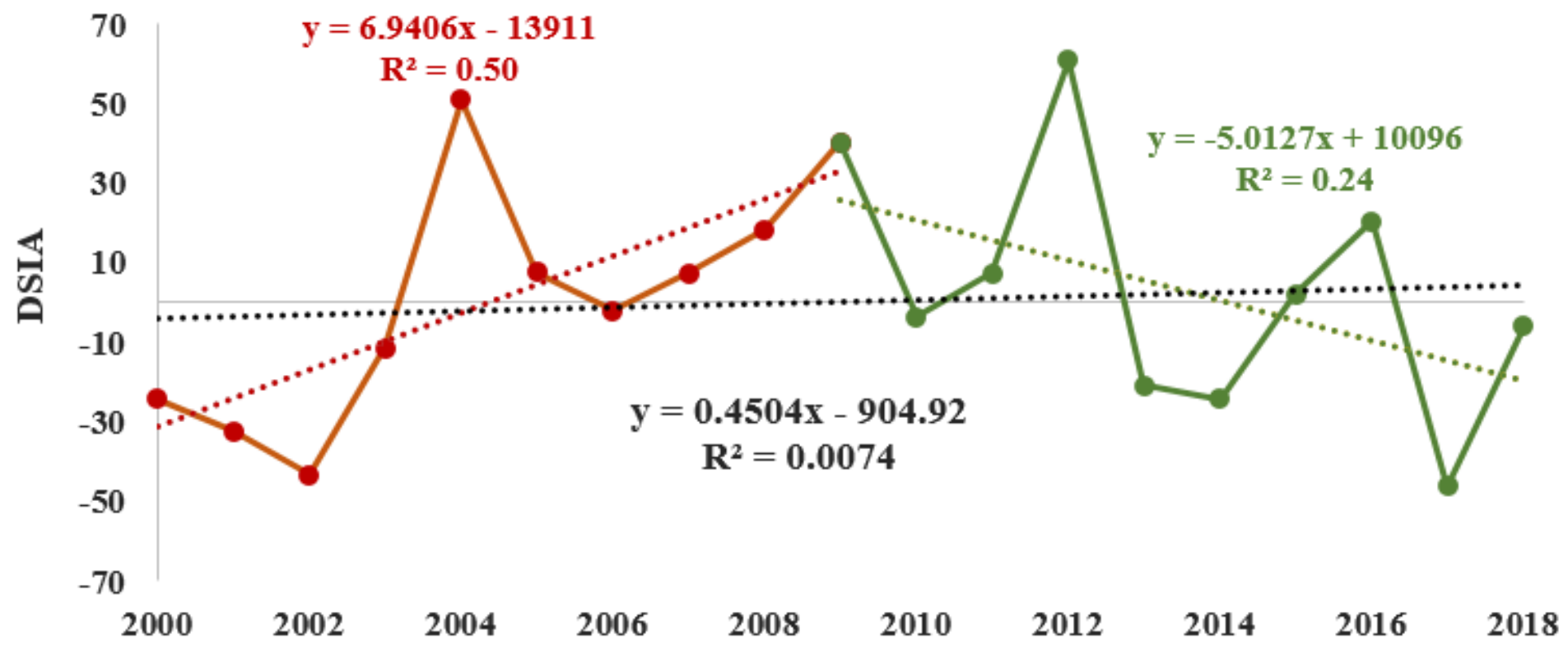

Figure 4

Inter-annual variations in dust storm index anomalies (DSIA) across western Iran during the years 20002018. The overall slope of the temporal changes in the DSIA during the period 2000 to 2008, 2009 to 2018 and the whole study period are shown with red, green and black dotted lines, respectively.

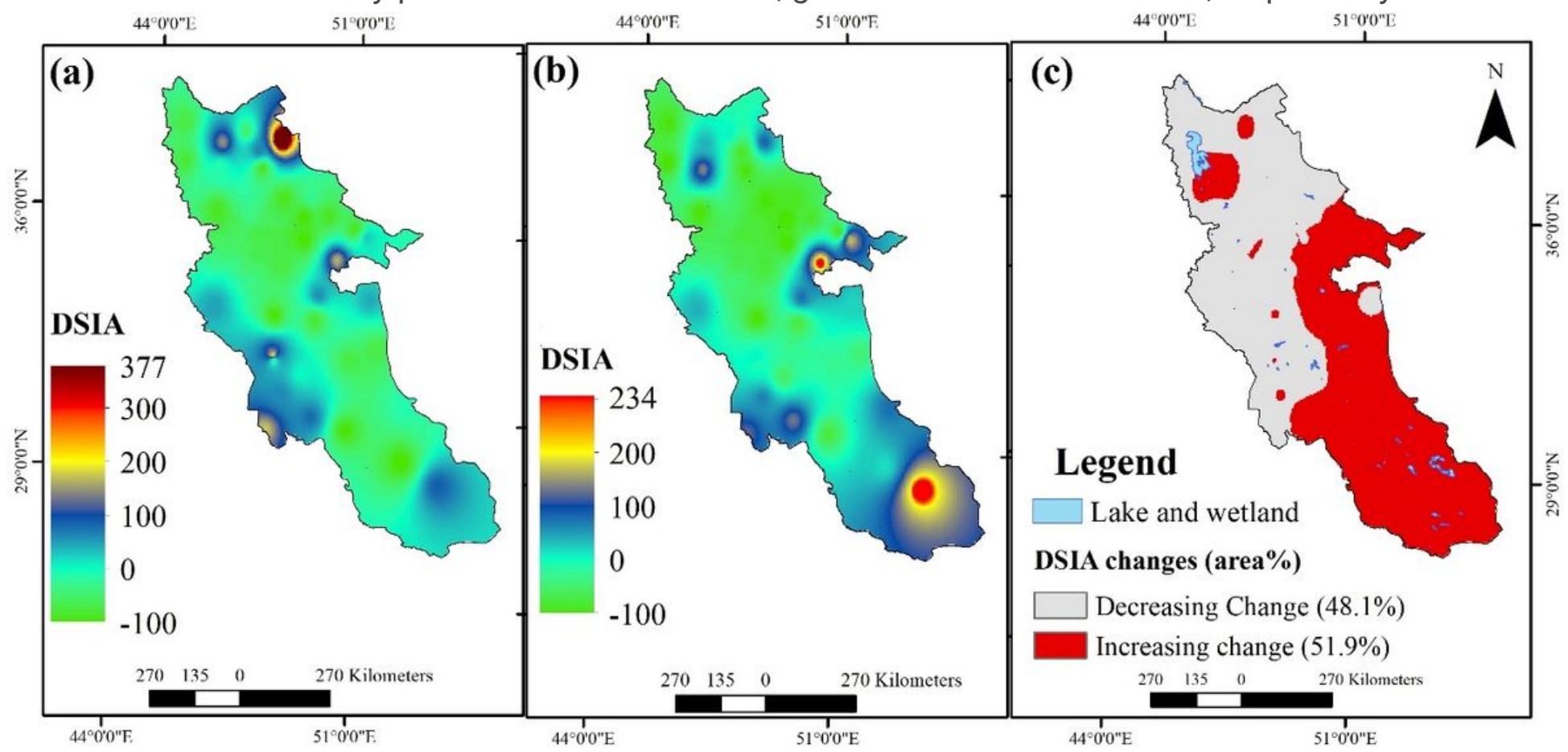

Figure 5

The DSIA variations across two separate periods: (a) 2000-2009 and (b) 2010-2018, and (c) its changes trend between two sub-periods. 
(a)

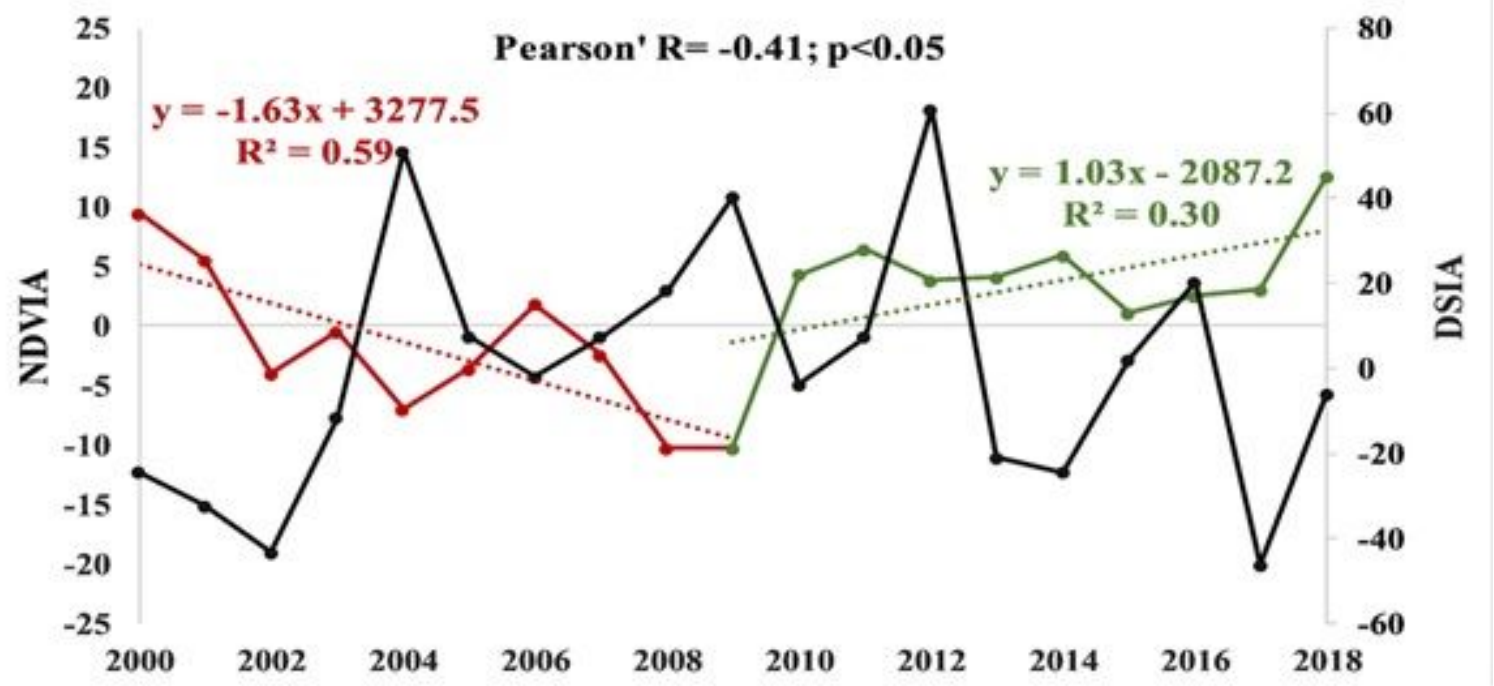

(b)

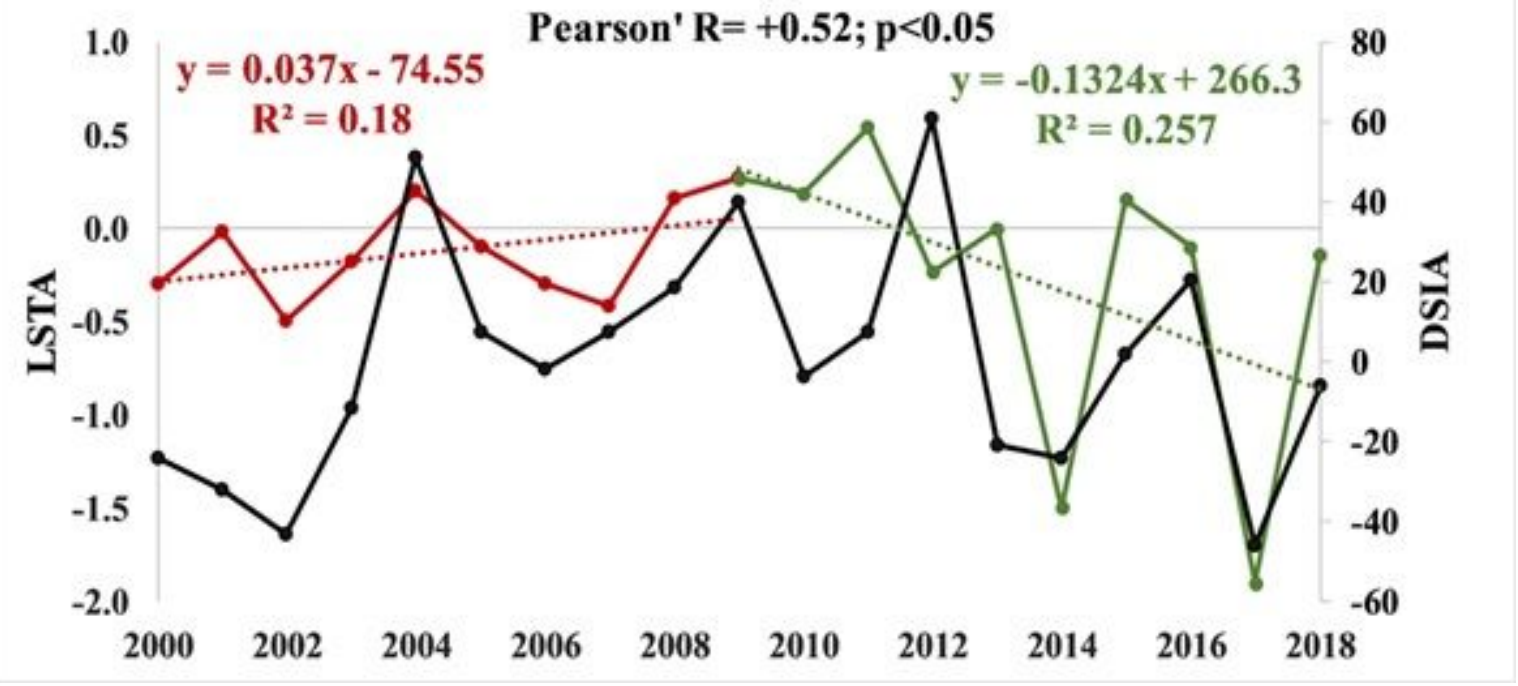

Figure 6

Inter-annual variations in the (a) LST anomaly; (b) NDVI anomaly and their relation with DSIA in western Iran during 2000-2018. 


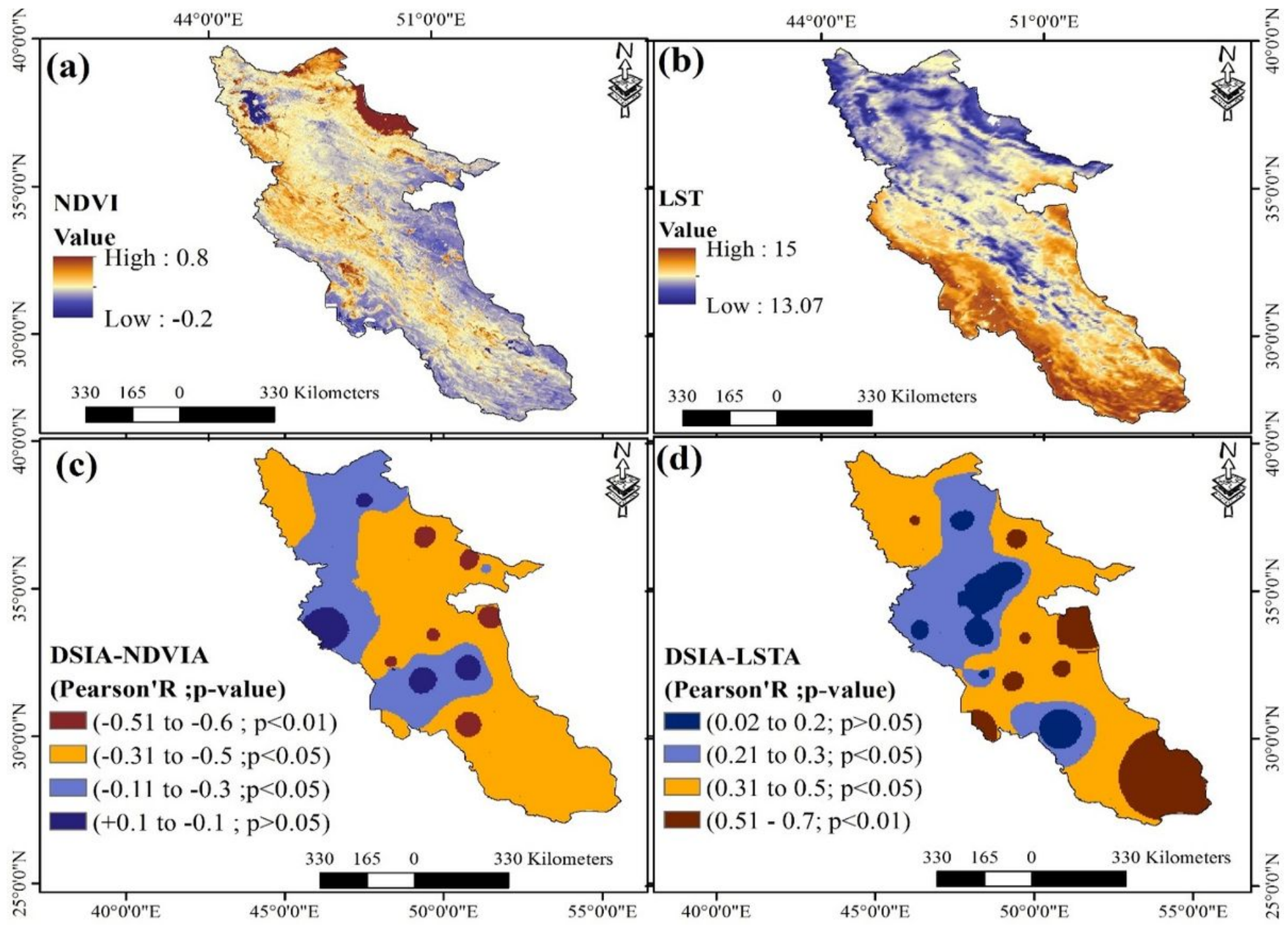

Figure 7

Spatial variations of (a) vegetation cover and (b) land surface temperature across western Iran. Spatial correlation coefficients between DSIA with (c) NDVIA and (d) LSTA in the area during 2000-2018. 


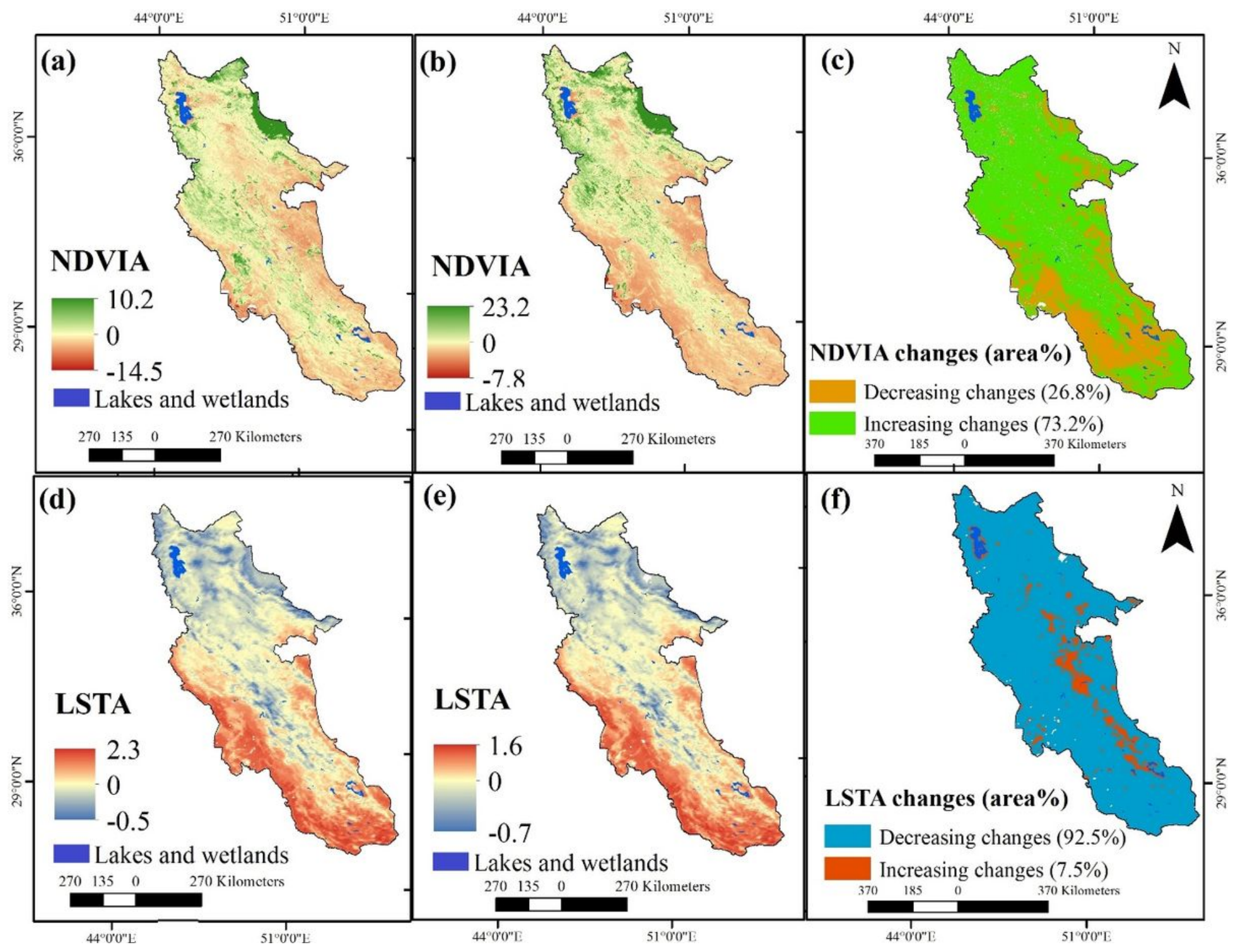

Figure 8

The periodic variations in NDVI anomaly and LST anomaly over study periods: (a;d) 2000-2009 and (b;e) 2010-2018. Trends of changes in vegetation anomaly (c) and land surface temperature anomaly (f) between two periods.

\section{Supplementary Files}

This is a list of supplementary files associated with this preprint. Click to download.

- Supplementaryfiles.docx 